\title{
0 poder da escravidão: um comentário aos "Senhores sem escravos"
}

The Power of Slavery: a Comment on

"Senhores sem escravos"

Rafael de Bivar Marquese

Professor no Departamento de

História da Universidade de São Paulo

\section{Resumo}

0 artigo comenta o texto de Keila Grinberg, "Senhores sem escravos", com base em dois pontos. 0 primeiro trata dos significados macro-políticos das ações de escravidão estudadas por Grinberg, ressaltando, com isso, o papel do Estado no conjunto das relações escravistas. 0 segundo aborda o conceito de sociedade escravista, com o objetivo de indicar a necessidade de esforços teóricos adicionais para se dar conta da especificidade do escravismo brasileiro.

\section{Abstract}

The article comments Keila Grinberg's article, "Masters without slaves", focusing on two themes. The first deals with the macro-political meanings of the slave lawsuits studied by Grinberg, regarding the State's role in the social relations of slavery. The second approaches the concept of slave society to indicate the need of additional theoretical efforts in order to comprehend the specificity of the Brazilian slave system.

\section{Palavras-chave}

escravidão, alforria, cidadania, Império do Brasil

\section{Keywords}

slavery, manumission, citizenship, Brazilian Empire 
GRINBERG, Keila. Senhores sem escravos: a propósito das ações de escravidão no Brasil Imperial. Revista Almanack Braziliense, São Paulo, N. 6, p.5, novembro 2007.

Ibidem, p.2.
Os pesquisadores da escravidão brasileira, ao se voltarem nas duas últimas décadas para a investigação sistemática em arquivos com o emprego de novas lentes teóricas, descortinaram aspectos antes insuspeitados de nosso passado escravista. Dentre o grande leque de temas investigados, as normas e práticas legais relacionadas ao cativeiro ocuparam papel de relevo. Como ressalta Keila Grinberg no artigo submetido a debate, "muitos historiadores, nos últimos anos, estudaram as formas pelas quais sistemas de direito simultaneamente contribuíram para perpetuar o poder dos proprietários sobre seus escravos e serviram como base a partir da qual escravos e libertos conseguiram desafiar o poder de seus senhores" 1. A autora destas palavras é, certamente, uma das especialistas que mais tem se destacado na exploração do assunto. Ela agora nos oferece um texto no qual propõe discutir as "práticas de re-escravização no Brasil do século XIX, refletindo sobre suas possibilidades efetivas e os significados a este processo atribuidos pelos diversos agentes sociais envolvidos" 2.

Meu rápido comentário procurará, por um lado, apontar para alguns dos significados macro-políticos das ações de escravidão estudadas por Grinberg, isto é, dos elementos estruturais que as conformaram. Quero, com isso, ressaltar o papel do Estado no conjunto das relações escravistas, algo que foi relativamente negligenciado pela historiografia da escravidão brasileira em seu movimento de renovação. Por outro lado, pretendo igualmente discutir em poucas linhas o conceito de sociedade escravista. 0 objetivo, aqui, é tão somente indicar a necessidade de esforços teóricos adicionais para se dar conta da especificidade da sociedade escravista brasileira.

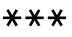

A principal conclusão do texto é a de que foram os senhores com poucas posses, não raro filhos e netos de ex-escravos ou eles próprios egressos do cativeiro, que, ao longo do século XIX, acionaram a justiça para reescravizar homens e mulheres usualmente libertados em testamento. Com poucos recursos físicos para impor sua vontade de poder, esses sujeitos contavam com o aparato do judiciário para manter a posição senhorial, 0 que fizeram com afinco muito em razão de um quadro econômico mais amplo que, a partir da década de 1830, trouxe elevação substantiva nos valores dos escravos. Tal descoberta empírica, por si instigante, todavia suscita uma pergunta que não foi formulada pela autora: o que essas práticas revelam sobre a natureza do Estado nacional e da sociedade escravista brasileira no século XIX?

Para encaminhar uma possivel resposta à indagação, é útil lembrar a diferença que o sociólogo Orlando Patterson estabelece entre os determinantes privados e os determinantes públicos da relação escravista. 0 ajuste do escravo à sua condição englobou sempre dois eixos: suas relações diretas com seu senhor e suas relações com a comunidade externa aos laços de subordinação pessoal; mediando-as, haveria um terceiro eixo de relações, aquelas entre seu senhor e comunidade externa. Os determinantes privados se reportavam ao primeiro eixo, ao passo que os determinantes públicos diziam respeito ao segundo e terceiro eixos. Nos termos de Patterson, "o senhor, não obstante quão independente desejasse ser nas relações com seu escravo, precisava de sua comunidade tanto para confirmar como para sustentar seu poder". Comunidade, aqui, deve ser entendida em um sentido lato, englobando não apenas o conjunto dos demais senhores de escravos e homens livres como 
PATTERSON, Orlando. Slavery and Social Death. A Comparative Study. Cambridge, Mass.: Harvard University Press, 1982. p.172-3.

GRINBERG, Keila. Senhores sem escravos: a propósito das ações de escravidão no Brasil Imperial. Revista Almanack Braziliense, São Paulo, N. 6, p.12, novembro 2007.

SALLES, Ricardo. E o escravo era o Vale Vassouras, século XIX. Senhores e escravos no coração do Império. Rio de Janeiro: Civilização Brasileira, no prelo.

Para o exame desta matéria no âmbito do Parlamento brasileiro, ver PARRON, Tâmis Peixoto. A política do tráfico negreiro no Império do Brasil, 1826 a 1850. Relatório Final de Iniciação Científica. São Paulo: DH/FFLCH/ USP, 2006.

Ver, a respeito, os trabalho de Grinberg cita na nota 3 de seu artigo.

\section{8}

Os artigos em questão são os seguintes: GRINBERG, Keila, "Reescravização, direitos e justiças no Brasil do século XIX"; MAMIGONIAN, Beatriz Gallotti, "O direito de ser africano livre. Os escravos e as interpretações da lei de 1831"; AZEVEDO, Elciene, "Para além dos tribunais. Advogados e escravos no movimento abolicionista em São Paulo". In: LARA, Silvia Hunold; MENDONÇA, Joseli Maria Nunes (org.) Direitos e Justiças no Brasil. Ensaios de História Social. Campinas: Ed.Unicamp, 2006 igualmente o poder político. Patterson adverte ainda que essas correlações variaram no tempo e no espaço, conforme as respostas dos escravos à sua condição, a composição das camadas senhoriais e o caráter do poder político em questão. ${ }^{3}$ Ou seja, caso não se leve em conta a natureza do Estado e suas relações com homens livres e escravizados, não será possivel compreender devidamente a sociedade escravista submetida a exame.

Grinberg anota em seu texto que não encontrou, na centena de casos que consultou, "senhores de muitas posses envolvidos, em nenhuma época do século XIX, em nenhuma região" 4 . Pode-se afirmar que os grandes proprietários não recorreram à justiça para re-escravizar ex-cativos ou indivíduos nascidos livres por terem recursos físicos e materiais para impor seu domínio. 0 braço do Estado era por eles mobilizado apenas em casos extremos de contestação, como fugas coletivas ou rebeliões. Os escravos que escapavam de suas garras em fugas individuais se viam perseguidos por capitães do mato e anúncios na imprensa, e seus nomes eram arrolados - mesmo que longos anos após a evasão - nos inventários post-mortem. É bem provável que os pequenos proprietários analisados por Grinberg, quando diante da fuga de seus cativos, recorressem aos mesmos recursos, mas o fato de somente eles abrirem ações de escravidão indica uma clara assimetria nas relações dos diferentes senhores com o Estado.

Que os pequenos proprietários contavam com o apoio estatal para a manutenção de seu poder, comprovam-no os diversos casos arrolados por Grinberg. A justiça - vale dizer o Estado - era vista como a instância que sancionava a escravidão. Um claro indicativo disto é dado pelo gráfico 4, que se remete à pesquisa de Ricardo Salles sobre Vassouras no século XIX: por meio da leitura de seus resultados, observa-se que as grandes escravarias desse municipio cafeeiro foram montadas nas décadas de 1830 e 1840, durante a vigência do tráfico transatlântico ilegal, proibido nas letras da lei por decreto regencial de 7 de novembro de 1831.5 Torna-se evidente, portanto, que os determinantes públicos da escravidão no Império do Brasil ofereceram as condições políticas e jurídicas para que os proprietários possuidores de africanos ilegalmente escravizados se sentissem seguros no domínio de seus cativos. ${ }^{6}$ Esse poder concentrado nas mãos dos senhores foi percebido com nitidez pelos grupos sociais subalternos, como se nota em vários temores populares citados por Grinberg a respeito das práticas concretas de re-escravização no Império.

Os trabalhos anteriores da autora e de outros historiadores, no entanto, registraram como esse mesmo Estado reconhecia com freqüência a liberdade de escravos por meio de ações impetradas em seus tribunais. ${ }^{7}$ A explicação que a historiografia tem dado a este aparente paradoxo aponta - sob a inspiração de E.P.Thompson - como a esfera jurídica operou no Brasil e alhures como um campo de lutas e contestações. Mas a constatação, caso se esgote em si, não nos ajuda a avançar muito. Veja-se o exemplo de uma boa coletânea recente a respeito dos direitos na história do Brasil. Alguns dos historiadores que nela colaboraram, ao examinarem o tema da escravidão, documentaram a inflexão que houve, a partir de meados da década de 1860, nas batalhas entre senhores e escravos no campo judicial, quando se inverteram tendências anteriores que favoreciam os proprietários em ações de liberdade ou na interpretação do conteúdo da lei de 1831.8 Nenhum desses autores - dentre os quais se inclui Grinberg - avançou uma explicação substantiva para tal virada. No artigo que ora discutimos, a análise se encerra no início da década de 1870. Não sabemos porque Grinberg procedeu desta forma, mas creio que não é descabido aventar que algo semelhante ao que identificou nos 
9

Tal idéia foi desenvolvida em dois artigos que escrevi com Márcia Regina Berbel, no âmbito do Projeto Temático A fundação do Estado e do nação: "La esclavitud en las experiencias constitucionales ibéricas, 1810-1824". In: FRASQUET, Ivana (org.). Bastillas, cetros y blasones. La Independencia en Iberoamérica. Madri: Fundación Mapfre-Instituto de Cultura, 2006; "The absence of race: slavery, citizenship, and pro-slavery ideology in the Cortes of Lisbon and in the Rio de Janeiro Constituent Assembly (1821-1824)". In: Social History, 32 (4): p. 415-33, November 2007.

\section{0}

MARQUESE, Rafael de Bivar. "A dinâmica da escravidão no Brasil. Resistência, tráfico negreiro e alforrias, séculos XVII a XIX." In: Novos Estudos CEBRAP, N.74: p.107-23, março de 2006.

\section{1}

A relação entre esses processos é examinada por COSTA, Emilia Viotti da. "Brasil: A Era da Reforma, 1870-1889". In: BETHELL, Leslie. (org.) História da América Latina. Vol.5: De 1870 a 1930. (trad.port.) São Paulo: EduspFunag, 2002, p.735-41, e por GRAHAM, Richard. Clientelismo e Politica no Brasil do século XIX. (trad.port.) Rio de Janeiro: Ed.UFRJ, 1997, p.239-63. Sobre a cisão entre Estado e senhores com a Lei do Ventre Livre, ver CARVALHO, José Murilo de. A construção da ordem/Teatro de Sombras. (4a ed.) Rio de Janeiro: Civilização Brasileira, 2006. p.322.

\section{2}

Cf. DAVIS, David Brion. The Problem of Slavery in the Age of Revolution, 1770-1823. (1a.ed: 1975). New York: Oxford University Press, 1999, p.471-8; DRESCHER, Seymor. Capitalism and Antislavery. British Mobilization in Comparative Perspective. New York: Oxford University Press, 1987. p.36-42. casos examinados em seu artigo inscrito na mencionada coletânea tenha aqui se verificado, isto é, uma sensivel diminuição nas ações de escravidão após fins da década de 1860 .

Supondo correta a hipótese de que as ações de escravidão refluíram a partir dessa data, pode-se propor um enquadramento mais amplo para a questão. A Constituição do Império do Brasil foi firmada, em 1824, projetando o futuro com base na escravidão negra. A consulta dos diários das Cortes de Lisboa (1821-1822) e da Assembléia Constituinte do Rio de Janeiro (1823) permite ver como esse compromisso com o porvir do escravismo foi equacionado justamente por meio da definição do estatuto que os egressos do cativeiro teriam na ordem social e política do novo Estado nacional. ${ }^{9}$ Noutros termos, os atores sociais que construiram o arranjo constitucional brasileiro atrelaram a manutenção do escravismo e do tráfico negreiro à concessão da cidadania para os libertos nascidos no Brasil, valendo-se, para tanto, de uma leitura particular da dinâmica da escravidão na América portuguesa, que combinava o assombroso volume do trato transatlântico com taxas relativamente elevadas de alforria. ${ }^{10} \mathrm{Em} \mathrm{1850,} \mathrm{a} \mathrm{equação} \mathrm{tráfico} \mathrm{negreiro} \mathrm{/} \mathrm{altos}$ indices de manumissão / cidadania para libertos brasileiros e seus descendentes parece ter sofrido revés. Há indícios consistentes de que, em uma espécie de ajuste para a reprodução demográfica da escravidão, as taxas de alforria diminuiram de modo sensivel, em diferentes espaços no Brasil, com o fim definitivo do tráfico transatlântico. 0 ponto de inflexão decisivo, contudo, veio somente em 1871. A aprovação da Lei do Ventre Livre - a primeira disjunção profunda entre Estado imperial e classes senhoriais - representou um obstáculo concreto à expansão da escravidão, e, não por acaso, abriu caminho para a articulação do movimento antiescravista e para a reforma eleitoral de 1881, o que, por sua vez, quebrou com o esquema de participação política dos libertos desenhado pela Constituição de $1824 .{ }^{11}$

Não cabe aqui discutir as diversas explicações fornecidas pela historiografia para a gênese da Lei do Ventre Livre, mas simplesmente destacar que, até aquela data, as opiniões antiescravistas correntes no Brasil desde a década de 1820 não haviam conseguido se estruturar em um movimento político orgânico. 0 contraste com outros espaços é elucidativo. 0 famoso episódio Somerset, ocorrido na Inglaterra em 1772, se do ponto de vista formal não constituiu uma ação de escravidão ou de liberdade tal como as que Grinberg analisou para o Brasil, não obstante envolveu a esfera judicial na deliberação da condição civil (livre ou escrava) de um cativo do Novo Mundo. James Somerset era um escravo virginiano que havia se mudado com seu senhor para a Inglaterra. 0 proprietário, desejando retornar à América, porém enfrentando a resistência do cativo, acorrentou-o em um barco destinado à Jamaica. Somerset, então, com o auxilio dos antiescravistas ingleses, deu início a um pleito judicial demandando sua liberdade. A decisão final do caso em 1772, favorável a Somerset, sugeria que a escravidão era incompativel com as leis da Inglaterra, e, por este motivo, gerou grande comoção pública, levando vários contemporâneos e futuros historiadores a enxergá-lo como o ponto fundador na história do movimento antiescravista inglês. ${ }^{12}$ Ora, nenhuma ação de liberdade ou de escravidão no Brasil monárquico foi capaz de catalisar as vozes antiescravistas, convertendo-as em movimento político. A fissura que permitiu isso partiu do próprio Estado, quando o Imperador - via Conselho de Estado - colocou na agenda do Império, muito em resposta ao resultado da Guerra Civil norte-americana e ao quadro imediato da Guerra do Paraguai, a questão da abolição gradual do cativeiro por meio da libertação do ventre das escravas. 
13

Cf. FINLEY, M.I. "Slavery". In: International Encyclopedia of the Social Sciences. New York: Macmillan, 1968, v.13, p.307-13; BERLIN, Ira. Generations of Captivity. A History of AfricanAmerican Slaves. Cambridge, Mass.: Belknap Press of Harvard University Press, 2003.

\section{4}

Refiro-me, evidentemente, ao livro Escravidão antiga e ideologia moderna. (1 $1^{\text {a }}$ ed: 1980; trad. port.) Rio de Janeiro: Graal, 1991. A critica a Finley se baseia no capítulo primeiro de JOLY, Fábio Duarte. Libertate opus est. Escravidão, Manumissão e Cidadania à Época de Nero (5468 d.C.). Tese de Doutorado em História. São Paulo: FFLCH/USP, 2006.

\section{5}

Os trabalhos recentes de Joseph C. Miller têm destacado bastante esse ponto. Ver, dentre outros, seus artigos "Stratégies de marginalité. Une approche historique de l'utilisation des êtres humains et des ideologies de l'esclavage: progéniture, piété, protection personele et prestige - produit et profits des propriétaires". In: HENRIQUES, Isabel C. e SALA-MOULINS, Louis (org.) Déraison, esclavage et droit: lês fondements idéologiques et juridiques de la traite négrière et de l'esclavage. Paris: Ed.Unesco, 2002, e "A Theme in Variations: A Historical Schema of Slaving in the Atlantic and Indian Ocean Regions". In: Slavery \&t Aboliton, 25 (2), p. 169-94, August 2004.

16

Ver, afora o livro de Patterson citado na nota 4, o ensaio de KOPYTOFF, Igor. "Slavery". In: Annual Review of Anthropology, N.11: p.20730, 1982.

Recebido para publicação em setembro de 2007
Resta, contudo, o fato de as ações de liberdade terem sido bastante comuns no Brasil. Aqui nos aproximamos do problema da natureza da sociedade escravista brasileira. Grinberg ressalta que as ações de escravização foram aparentemente exclusivas do Brasil. Já gozávamos das duvidosas honrarias de sermos a região que mais importou escravos da África e o último país do ocidente que aboliu a escravidão. E por que tais ações judiciais só se fizeram presentes nestas paragens? A resposta me parece simples. Não houve, em outros espaços americanos, uma combinação equivalente de tráfico transatlântico elevadissimo e prática ampla e disseminada da alforria. Foi a produção constante de grupos sociais egressos do cativeiro que levou pequenos proprietários, também egressos do cativeiro, a acionarem a justiça para manter sua posição de senhores.

A particularidade nos remete diretamente ao conceito de sociedade escravista. Como se sabe, a partir de fins da década de 1960 ganhou popularidade entre os especialistas a formulação de Moses Finley, que diferenciou as sociedades com escravos das sociedades genuinamente escravistas pela centralidade da instituição, nessas últimas, para a produção material e o modo de vida de suas elites dominantes. A discussão foi atualizada recentemente por Ira Berlin, que procurou imprimir dinamismo ao conceito ao examinar as variações da escravidão em solo norte-americano, no tempo e no espaço. ${ }^{13}$ No entanto, tanto em um como em outro autor, a alforria está ausente do horizonte teórico. Para Berlin, a restrição acentuada das manumissões seria inclusive um dos traços que marcariam a passagem de uma sociedade com escravos para uma sociedade genuinamente escravista. Esse enquadramento historiográfico deita suas raízes na virada do século XVIII para o século XIX, mais precisamente no movimento antiescravista anglo-saxônico e francês, a matriz dos primeiros estudos sistemáticos da escravidão greco-romana e da própria escravidão moderna. Os abolicionistas oitocentistas tinham em mira os sistemas do Caribe e do Sul dos Estados Unidos, que se caracterizavam justamente pela virtual ausência de alforrias. Deste foco político, elaborou-se uma idéia de escravidão que a concebia como uma relação que contrapunha em termos absolutos senhores e escravos, concepção esta que encontrou larga carreira nas pesquisas históricas sobre a instituição. Em que pese toda sua avaliação erudita a respeito do papel da ideologia moderna na configuração dos estudos sobre a escravidão antiga, Finley caiu na mesma armadilha que procurou criticar, ao não enxergar o papel estruturante que as manumissões tiveram para o escravismo no mundo romano. ${ }^{14}$

Berlin ao menos é cuidadoso ao caracterizar o peso diferenciado da alforria em diferentes tempos e espaços da história norte-americana. Seu modelo, porém, definitivamente não é válido para compreender o caso brasileiro. Na história dos processos globais de escravização, as sociedades que ingleses e franceses construiram a partir de fins do século XVII no Caribe e no Sul da América Setentrional representam a exceção, e não a regra, dentre outras coisas devido aos limites colocados à prática da alforria. ${ }^{15}$ Neste sentido, a abordagem proposta por Igor Kopytoff e Orlando Patterson, que encaram a escravização, a situação de escravidão e a manumissão como partes de um mesmo processo institucional, é bem mais operacional para dar conta de sociedades escravistas como a islâmica, a romana e a brasileira. ${ }^{16}$ 0 que falta aos modelos de Kopytoff e Patterson é a apreensão da historicidade da articulação de sistemas escravistas como o brasileiro à formação da economia-mundo capitalista. Se este não é o lugar apropriado para tocar adiante tal tarefa, não há dúvidas que trabalhos como os que Keila Grinberg vem nos oferecendo fornecem riquíssimo material empírico para tanto. 